\section{Coarctation of the Aorta in an Infant Exposed to Etanercept in Utero}

\section{To the Editor:}

We describe a case of coarctation of the aorta associated with exposure to etanercept during pregnancy. Our female patient was 27 years of age when she developed rapid onset of inflammatory polyarthritis in a symmetrical pattern, with a positive rheumatoid factor and erosions on hand and wrist radiographs. She was diagnosed with rheumatoid arthritis (RA). She was treated with serial disease-modifying antirheumatic drugs including hydroxychloroquine, methotrexate, leflunomide, and intermittent prednisone. Her arthritis was under control when she had a planned pregnancy in 2003 , at the age of 31 . She continued taking prednisone and hydroxychloroquine throughout this first pregnancy. She gave birth to a healthy girl at 35 weeks of gestation. In her postpartum period, she had persistent exacerbation of her RA. At 12 weeks' postpartum, she started etanercept $25 \mathrm{mg}$ subcutaneously (SC) twice weekly. Her joint inflammation improved significantly with etanercept, and over 1 year her prednisone was slowly tapered to $15 \mathrm{mg}$ daily.

In 2006, she decided to become pregnant for the second time. At that time, her RA was under control with prednisone $15 \mathrm{mg}$ daily and etanercept $25 \mathrm{mg}$ SC twice weekly. The unknown risks of etanercept during pregnancy were discussed and she decided to continue with the treatment. She was treated with etanercept $50 \mathrm{mg} \mathrm{SC}$ once weekly and prednisone $15 \mathrm{mg}$ daily. At 5 weeks of gestation, she decided to stop her etanercept and prednisone was increased to 20 to $40 \mathrm{mg}$ daily based on symptoms.

At 28 weeks of gestation, routine fetal monitoring revealed nonreassuring fetal heart rates necessitating emergency cesarean delivery of a male infant appropriate for gestational age. Pediatric consultation diagnosed hyaline membrane disease, coarctation of the aorta and associated bicuspid aortic valve with secondary hypertension, and retinopathy of prematurity. The baby was initially in neonatal intensive care but was well enough to be discharged home after corrective surgery. Several further cardiac surgeries were needed, but the baby died 8 months after delivery secondary to bleeding at the aorta surgical site within 24 hours of his last cardiac surgery. Death was due to a complication of surgery.

Congenital heart defects (CHD) occur in about $1 \%$ of liveborn infants, and of infants born with CHD, 7\% will have coarctation of the aorta ( $0.07 \%$ of liveborn infants). Coarctation of the aorta is more common in males than females and is frequently seen in patients with gonadal dysgenesis ${ }^{1}$. Our patient also had aortic valve dysplasia that was surgically repaired; however, there was no family history of CHD including coarctation of aorta. The hyaline membrane disease and retinopathy of the neonate were attributed to prematurity.

The US Food and Drug Administration categorizes etanercept as "category B" in pregnancy: "Animal reproduction studies have failed to demonstrate a risk to the fetus and there are no adequate and well controlled studies in pregnant women." One should note that animal pregnancies and human pregnancies differ in terms of placental physiology and maturation of the fetus ${ }^{2}$. Therefore, the lack of teratogenicity of the anti-tumor necrosis factor- $\alpha$ (anti-TNF- $\alpha$ ) drugs in animal studies does not preclude the possibility of birth defects in humans.

Several series of case reports and isolated case reports found no malformations associated with the use of etanercept in pregnancy ${ }^{3-7}$. A survey by Chakravarty, et al reported 15 pregnancies exposed to etanercept ${ }^{3}$. The 6 pregnancies with known outcomes in patients exposed to etanercept resulted in delivery of full-term healthy infants and no congenital malformations. However, there is one case report of a pregnant patient with psoriasis and psoriatic arthritis who took etanercept $50 \mathrm{mg} \mathrm{SC}$ twice weekly throughout her pregnancy and gave birth to a child with VATER (vertebrae and anal anomalies, tracheal and esophageal problems, radius or renal defects) association ${ }^{8}$.

The formation of the cardiovascular system begins during the third week of embryonic development and completes by the end of the eighth week. Generally the period between the fourth and sixth week is considered to be the most sensitive time of cardiovascular development ${ }^{9}$. Etanercept has an elimination half-life of 72 to 132 hours ( 3 to 5 days). In our case the embryo was exposed to etanercept in the first 5 weeks of gestation and therefore during the critical period of cardiovascular development.

We found no literature reports of coarctation of the aorta associated with exposure to etanercept during pregnancy. While our case does not demonstrate a causal relationship between etanercept exposure during pregnancy and coarctation of the aorta, it emphasizes the need for studies and registries that investigate and follow exposures of anti-TNF drugs in pregnancy.

IMAN HEMMATI, BSc, Faculty of Medicine; STEPHANIE ENSWORTH, MD, FRCPC, Division of Rheumatology, Faculty of Medicine; KAM SHOJANIA, MD, FRCPC, Head, Division of Rheumatology, Faculty of Medicine, University of British Columbia, 802 - 1200 Burrard Street, Vancouver, British Columbia V6Z 2C7, Canada. Address correspondence to Dr. Shojania.

E-mail: kam.shojania@vch.ca.

\section{REFERENCES}

1. Child JS, Friedman WF. Congenital heart disease in the adult. In: Fauci AS, Braunwald E, Kasper DL, Hauser SL, Longo DL, Jameson JL, et al, editors. Harrison's principles of internal medicine. 16th ed. New York: McGraw-Hill; 2005:1381-90.

2. Lockshin MD. Treating rheumatic diseases in pregnancy: dos and don'ts. Ann Rheum Dis 2006;65 Suppl 3:58-60.

3. Chakravarty EF, Sanchez-Yamamoto D, Bush TM. The use of disease modifying antirheumatic drugs in women with rheumatoid arthritis of childbearing age: a survey of practice patterns and pregnancy outcomes. J Rheumatol 2003;30:241-6.

4. Berthelot JM, De Bandt M, Goupille P, Solau-Gervais E, Lioté F, Goeb V, et al, on behalf of CRI (Club Rhumatismes et Inflammation). Exposition to anti-TNF drugs during pregnancy: outcome of 15 cases and review of the literature. Joint Bone Spine 2009;76:28-34.

5. Sills ES, Perloe M, Tucker MJ, Kaplan CR, Palermo GD. Successful ovulation induction, conception, and normal delivery after chronic therapy with etanercept: a recombinant fusion anticytokine treatment for rheumatoid arthritis. Am J Reprod Immunol 2001;46:366-8.

6. Sinha A, Patient C. Rheumatoid arthritis in pregnancy: successful outcome with anti-TNF agent (Etanercept). J Obstet Gynaecol 2006;26:689-91.

7. Feyertag J, Dinhof G, Salzer H, Dunky A. Pregnancy in a rheumatoid arthritis patient treated with etanercept. Ann Rheum Dis 2004;63 Suppl 1:198.

8. Carter JD, Valeriano J, Vasey FB. Tumor necrosis factor-alpha inhibition and VATER association: a causal relationship. J Rheumatol 2006;33:1014-7.

9. Moore KL, Persaud TVN. The cardiovascular system. In: Moore KL, Persaud TVN. The developing human. 8th ed. Philadelphia: Saunders; 2008:285-308.

J Rheumatol 2009;36:12; doi.10.3899/jrheum.090430 